\title{
Considerations regarding the alleged association between Herbalife products and cases of hepatotoxicity: a rebuttal
}

\author{
Anna Licata $\cdot$ Antonio Craxì
}

Received: 30 January 2014/Accepted: 17 February 2014/Published online: 26 February 2014 (C) SIMI 2014

\section{Dear Editor,}

We thank Dr. K Appelhans et al. for their comments [1] on our paper [2], published online first in April 2012. In our review, we aimed to draw the attention of physicians to the uncontrolled and increasingly alarming use of herbal products and dietary supplements in the general population. In fact, in Italy this phenomenon, though still limited, has rapidly increased over the last few years. Here, use of herbal medicine products has increased to $3.7 \%$, while in other countries consumption is higher, reaching $20 \%$ in the UK, and $40 \%$ in the USA. Young non-smoking women with a high level of education appear to be the most common consumers [3]. It seems that women use these products more than men do, particularly when herbal products or dietary supplements are used as "slimming aids." Many overweight people resort to herbal products because, in the absence of a strong motivation, conventional methods for losing weight, such as physical exercise and a low calorie diet, generally fail. Thus, considering how easy it is to find available dietary supplements or herbal products via the Internet, people purchase what they deem the correct preparation directly, without consulting a physician or pharmacist.

Italian law requires that the labels of these products include only nutritional and physiological properties; potential harmful effects are typically not listed. There are a number of slimming aids and weight loss products available on the internet, including ones manufactured by Herbalife, which in the past were also sold door to door.

\footnotetext{
A. Licata $(\bowtie) \cdot$ A. Craxì

Sezione di Gastroenterologia, DIBIMIS, Università di Palermo, 90127 Palermo, Italy

e-mail: annalisalicata@yahoo.com; anna.licata@unipa.it
}

In our review [2], we listed the Herbalife products in Table 2. Since 2005, there have been more than 50 reported cases, from a variety of countries, of suspected hepatoxicity related to Herbalife products, which are often used as slimming aids. Most of the data regarding these cases are reported in various issues of the Journal of Hepatology (we cannot cite them all due to limited space here in the bibliography). These cases have raised safety concerns, and an interesting and ongoing debate over the identification of the presence of one or more hepatotoxic components. These products are marketed as foods, meal replacements, and dietary supplements, with different formulations and hundreds of ingredients, among which green tea extracts and aloe vera, about which there are welldocumented reports of hepatotoxicity, though the labels do not specify the type of substances (e.g., green tea extracts) or the amounts of active substances. As also reported by the manufacturer [1], some formulations are adapted to the target country or region, and sometimes more than one product (e.g., weight loss kit) is used simultaneously. As a result, it is extremely difficult to identify the toxins or substances responsible for the hepatotoxicity.

We agree with other authors (reference 73 of our review) that genetic susceptibility might be at the basis mechanisms of hepatotoxicity, and that some ingredients in the Herbalife formulations may be responsible for immunemediated liver damage that resembles a clinical picture of autoimmune disease, as has been reported in cases from Israeli, Swiss and Spain. Considering that there are about 53 reported cases, and Herbalife products are available in more than 88 markets [1], an idiosyncratic reaction against one or more ingredients would appear to be a plausible explanation. Therefore, considering the extreme difficulty of identifying the essential component(s) responsible for hepatotoxicity, despite efforts made by the manufacturer to 
cooperate with the regulatory agencies, we correctly stated that the suspected toxin is still unknown.

In addition, we also stated that a possible cause of hepatotoxicity linked to Herbalife products is the hypothesis of contamination with Bacillus subtilis in some batches (reference 77 in our review), and the possible, though still unproven, contamination of the substrates from which raw herbs are extracted. This latter possibility is plausible, and has been linked to other herbal products, such as KavaKava, and the culprit hepatotoxins pipermethystine and flavokavaine B [4].

Regarding the case series from Israel, Switzerland, Spain, Argentina and Iceland, Teschke et al. [5] have addressed a number of the relevant issues concerning the problem of causality assessment and rechallenge. In our review, published before these articles were available, we referred only to the already reported cases identified by widely used causality assessment scores as probable, avoiding a discussion of their reliability. The weaker causality score reassigned, further identification of potential causative factors, and the evaluation of the rechallenge in only one of the eight cases already suspected for positive rechallenge, surely reduce the causality level previously assigned to the cases involving Herbalife products. They do not, however, exclude causality for the other patients reported, identified as suffering from possible Herbalife product hepatotoxicity.

A greater understanding of these data will, we hope, lead to awareness in physicians of potential problems, either when patients disclose the use of these, or even when they simply express the intention to buy and use them.

Conflict of interest None to declare.

\section{References}

1. Appelhans K, Najeeullah R, Frankos V (2014) Considerations regarding the alleged association between Herbalife products and cases of hepatotoxicity. Intern Emerg Med. doi:10.1007/s11739-014-1048-9

2. Licata A, Macaluso FS, Craxì A (2013) Herbal hepatotoxicity: a hidden epidemic. Intern Emerg Med 8(1):13-22

3. Vitalone A, Menniti-Ippolito F, Moro P, Firenzuoli F, Raschetti R, Mazzanti G (2011) Suspected adverse reactions associated with herbal products used for weight loss: a case series reported to the Italian National Institute of Health. Eur J Clin Pharmacol 67:215-224

4. Teschke RR, Qiu SX, Lebot V (2011) Herbal hepatotoxicity by kava: update on pipermethystine, flavokavain $\mathrm{B}$, and mould hepatotoxins as primarily assumed culprits. Dig Liver Dis 43(9):676-681

5. Teschke R, Frenzel C, Schulze J, Schwarzenboeck A, Eickhoff A (2013) Herbalife hepatotoxicity: evaluation of cases with positive reexposure tests. World J Hepatol 5(7):353-363 